\title{
Authors' Responses to Peer Review of "Influence of the COVID-19 Lockdown on the Physical and Psychosocial Well-being and Work Productivity of Remote Workers: Cross-sectional Correlational Study"
}

Yessica Abigail Tronco Hernández ${ }^{1}$, BSc, MSc, PhD; Fabio Parente ${ }^{2}, \mathrm{BA}, \mathrm{MRes}, \mathrm{PhD}$; Mark A Faghy ${ }^{3}$, BSc, PhD; Clare M P Roscoe 3 , BSc, MSc, PhD; Frances A Maratos ${ }^{2}, \mathrm{BSc}, \mathrm{PhD}$

\footnotetext{
${ }^{1}$ School of Health Professions, University of Plymouth, Plymouth, United Kingdom

${ }^{2}$ School of Psychology, College of Health, Psychology and Social Care, University of Derby, Derby, United Kingdom

${ }^{3}$ School of Human Sciences, College of Science and Engineering, University of Derby, Derby, United Kingdom
}

\section{Corresponding Author:}

Fabio Parente, BA, MRes, PhD

School of Psychology

College of Health, Psychology and Social Care

University of Derby

Kedleston Road

Derby, DE22 1GB

United Kingdom

Phone: 447557952316

Email: f.parente@derby.ac.uk

\section{Related Articles:}

Preprint (PsyArXiv): https://psyarxiv.com/dnuk3/

Peer-Review Report by Anonymous https://med.jmirx.org/2021/4/e34607/

Peer-Review Report by Laura Taraboanta (Reviewer AB): https://med.jmirx.org/2021/4/e34608/

Published Article: https://med.jmirx.org/2021/4/e30708/

(JMIRx Med 2021;2(4):e34609) doi: 10.2196/34609

This is the authors' response to peer-review reports for the paper "Influence of the COVID-19 Lockdown on the Physical and Psychosocial Well-being and Work Productivity of Remote Workers: Cross-sectional Correlational Study”.

\section{Round 1 Review}

\section{Anonymous}

We are thankful to the reviewer [1] for the helpful suggestions regarding background literature. The first study is now mentioned in the first paragraph of the Introduction [2], in the context of income loss as a result of lockdown restrictions. The second study is now discussed in the first paragraph of the Implications section, in the context of a return to office-based work and contingencies that employers can implement to improve the psychophysical well-being of their workers.

\section{Reviewer AB}

1. We are grateful to the reviewer [3] for the positive review of our manuscript.

2. We agree! Indeed, there is some scope within our project to track down a few of our respondents to assess changes in their psychophysical well-being and work productivity since their first survey response, particularly now that the United Kingdom appears set to begin lifting most lockdown restrictions and to rescind the recommendation that people work from home where possible. We will consider the possibility and produce a follow-up study should this prove feasible (eg, sufficient sample size).

\section{Further Amendments}

In addition to addressing the reviewers' comments, we have taken heed of the editorial recommendations and implemented the following changes:

- Ensured the structured abstract has the recommended section headings.

- Ensured the major headings follow the IMRD schema.

- Ensured the major headings and subheadings follow the Microsoft Word style guidelines.

- Amended Table 3 as per the caption to ensure a good portrait fit.

- Changed all in-text citations from a superscript format to an [n] format. 
We believe these changes have resulted in an improved revised manuscript, and we hope you will find they have been addressed satisfactorily.
We look forward to receiving an outcome regarding the publication of our manuscript in JMIRx Med.

\section{References}

1. Anonymous. Peer review of "Influence of the COVID-19 Lockdown on the Physical and Psychosocial Well-being and Work Productivity of Remote Workers: Cross-sectional Correlational Study". JMIRx Med 2021 [FREE Full text] [doi: 10.2196/34607]

2. Tronco HYA, Parente F, Faghy MA, Roscoe CMP, Maratos FA. Influence of the COVID-19 lockdown on the physical and psychosocial well-being and work productivity of remote workers: cross-sectional correlational study. JMIRx Med 2021 [FREE Full text] [doi: 10.2196/30708]

3. Taraboanta L. Peer review of "Influence of the COVID-19 Lockdown on the Physical and Psychosocial Well-being and Work Productivity of Remote Workers: Cross-sectional Correlational Study". JMIRx 2021 [FREE Full text] [doi: $10.2196 / 34608]$

Edited by E Meinert; this is a non-peer-reviewed article. Submitted 01.11.21; accepted 01.11.21; published 01.12.21.

Please cite as:

Tronco Hernández YA, Parente F, Faghy MA, Roscoe CMP, Maratos FA

Authors' Responses to Peer Review of "Influence of the COVID-19 Lockdown on the Physical and Psychosocial Well-being and Work

Productivity of Remote Workers: Cross-sectional Correlational Study"

JMIRx Med 2021;2(4):e34609

URL: https://med.jmirx.org/2021/4/e34609

doi: $\underline{10.2196 / 34609}$

PMID:

(C) Yessica Abigail Tronco Hernández, Fabio Parente, Mark A Faghy, Clare M P Roscoe, Frances A Maratos. Originally published in JMIRx Med (https://med.jmirx.org), 01.12.2021. This is an open-access article distributed under the terms of the Creative Commons Attribution License (https://creativecommons.org/licenses/by/4.0/), which permits unrestricted use, distribution, and reproduction in any medium, provided the original work, first published in JMIRx Med, is properly cited. The complete bibliographic information, a link to the original publication on https://med.jmirx.org/, as well as this copyright and license information must be included. 